\title{
Biofilms formed by Candida albicans bloodstream isolates display phenotypic and transcriptional heterogeneity that are associated with resistance and pathogenicity
}

Leighann Sherry ${ }^{1}$, Ranjith Rajendran ${ }^{1}$, David F Lappin ${ }^{1}$, Elisa Borghi², Federica Perdoni ${ }^{2}$, Monica Falleni Delfina Tosi ${ }^{3}$, Karen Smith ${ }^{4}$, Craig Williams ${ }^{4}$, Brian Jones ${ }^{5}$, Chris J Nile ${ }^{1}$ and Gordon Ramage ${ }^{{ }^{*}}$

\begin{abstract}
Background: Candida albicans infections have become increasingly recognised as being biofilm related. Recent studies have shown that there is a relationship between biofilm formation and poor clinical outcomes in patients infected with biofilm proficient strains. Here we have investigated a panel of clinical isolates in an attempt to evaluate their phenotypic and transcriptional properties in an attempt to differentiate and define levels of biofilm formation.

Results: Biofilm formation was shown to be heterogeneous; with isolates being defined as either high or low biofilm formers (LBF and HBF) based on different biomass quantification. These categories could also be differentiated using a cell surface hydrophobicity assay with $24 \mathrm{~h}$ biofilms. HBF isolates were more resistance to amphotericin B (AMB) treatment than LBF, but not voriconazole (VRZ). In a Galleria mellonella model of infection HBF mortality was significantly increased in comparison to LBF. Histological analysis of the HBF showed hyphal elements intertwined indicative of the biofilm phenotype. Transcriptional analysis of 23 genes implicated in biofilm formation showed no significant differential expression profiles between LBF and HBF, except for Cdr 1 at 4 and $24 \mathrm{~h}$. Cluster analysis showed similar patterns of expression for different functional classes of genes, though correlation analysis of the $4 \mathrm{~h}$ biofilms with overall biomass at $24 \mathrm{~h}$ showed that 7 genes were correlated with high levels of biofilm, including Als3, Eap 1, Cph 1, Sap5, Plb1, Cdr1 and Zap1.
\end{abstract}

Conclusions: Our findings show that biofilm formation is variable amongst C. albicans isolates, and categorising isolates depending on this can be used to predict how pathogenic the isolate will behave clinically. We have shown that looking at individual genes in less informative than looking at multiple genes when trying to categorise isolates at LBF or HBF. These findings are important when developing biofilm-specific diagnostics as these could be used to predict how best to treat patients infected with C. albicans. Further studies are required to evaluate this clinically.

Keywords: Candida albicans, Biofilm, Candidaemia, Antifungal

\footnotetext{
* Correspondence: gordon.ramage@glasgow.ac.uk

${ }^{1}$ Infection and Immunity Research Group, Glasgow Dental School, School of Medicine, College of Medical, Veterinary and Life Sciences, University of Glasgow, 378 Sauchiehall Street, Glasgow G2 3JZ, UK

Full list of author information is available at the end of the article
} 


\section{Background}

Bloodstream infections (BSI) caused by Candida species remain a frequent cause of morbidity and mortality, particularly within the immunocompromised population $[1,2]$. Overall, Candida species have been identified as the most common fungal pathogen found in bloodstream infections in the United States, and are the fourth most common organism responsible for all BSI, and are the third most common within the intensive care unit (ICU) [2]. Candidaemia is often associated with the ability of Candida to adhere to and form biofilms on indwelling medical devices, such as central venous catheters (CVC) and prosthesis $[3,4]$. Biofilms are a population of microorganisms attached to one another and/or a surface, surrounded by an extracellular matrix (ECM) [5].

A defining feature of biofilms is their resistance to antimicrobial therapy, with higher drug concentrations required to kill biofilms and their dispersed cells when compared to equivalent free-floating planktonic cells [5-7]. Another feature of C. albicans biofilms is their enhanced pathogenicity. For example, cells detaching from biofilms have been shown to be more cytotoxic than their planktonic counterparts and significantly increase mortality within a murine model of infection [7]. These observations have been demonstrated clinically, where a significant association was observed between C. albicans biofilm formation and mortality rates in candidaemia patients [8].

Whilst there is growing evidence of the importance of Candida biofilms in clinical medicine, not all clinical isolates are able to form biofilms. There is therefore a fundamental gap in understanding exactly what drives biofilm formation and its clinical implications. Establishing methods to differentiate these isolates is challenging, as many studies rely on either metabolic assays or biomass, and these frequently use a variety of different substrates and media [9-12]. Therefore, comparison between these studies is not possible, and further interpretation of the data to improve clinical management both for diagnostics and antifungal therapy is limited. The purpose of this study was therefore to investigate and characterise biofilm formation by clinical isolates of $C$. albicans using standard methodologies and subsequently analyse biofilm subsets phenotypically and transcriptionally. Here we report that C. albicans clinical isolates form biofilms that are heterogeneous, and this is associated with altered antifungal drug sensitivity and pathogenic potential.

\section{Results}

\section{Candida albicans clinical isolates exhibit heterogeneous} biofilm formation

C. albicans bloodstream isolates displayed heterogeneity with respect to their biofilm biomass when grown in RPMI (Figure 1A). RPMI was shown to support the optimal growth of C. albicans over 24, 48 and $72 \mathrm{~h}$ (Additional file 1: Figure S1). Isolates were categorised as low biofilm formers (LBF) or high biofilm formers (HBF) if their biomass absorbance were less than the first quartile $\left(\mathrm{Q}_{1} \mathrm{OD}_{570}=0.565\right)$ or greater than the third quartile $\left(\mathrm{Q}_{3}\right.$ $\mathrm{OD}_{570}=1.682$ ), respectively. Those isolates in between the first and third quartile (Q1-Q3) were defined as intermediate biofilm formers. When HBF were stained with crystal violet (cv), the extent of the biofilm formation was observed macroscopically, where the bottom of the well was clearly covered with cellular biomass (Figure 1A). In contrast, minimal staining was retained on isolates classed as LBF, as demonstrated by the well remaining almost colourless. We analysed a subset of isolates from the LBF and HBF group $(\mathrm{n}=3)$ using dry weight measurements and confirmed our previous observations that biofilm biomass was significantly greater in isolates termed $\operatorname{HBF}(p=0.0023)$ (Figure $1 B)$. These differences are clearly evident when viewed under a SEM at low (Figure $1 \mathrm{C}$ [i, iii]) and high magnification (Figure 1C [ii, iv]). LBF isolates were characterised by a predominance of yeast cells and lack of hyphal cells (Figure $1 \mathrm{C} \mathrm{i,} \mathrm{ii).} \mathrm{In} \mathrm{contrast,} C$. albicans HBF were highly filamentous with a multi-dimensional structure with very few yeast cells (Figure $1 \mathrm{C}$ iii, iv).

\section{Biofilm phenotype is affected by cell surface hydrophobicity (CSH)}

The CSH of LBF and HBF isolates was quantified to determine whether it played a role in biofilm forming ability [13]. Figure 2 illustrates that the hydrophobicity of an isolate significantly alters its ability to form a biofilm. For LBF the $\mathrm{CSH}$ increased by $32 \%$ and $31 \%$ in $4 \mathrm{~h}(\mathrm{p}<0.05)$ and $24 \mathrm{~h}(\mathrm{p}<0.0005)$ biofilms, respectively, when compared to planktonic cells. This trend was also observed in isolates with $\mathrm{HBF}$ where $\mathrm{CSH}$ increased by $50 \%$ in $4 \mathrm{~h}(\mathrm{p}<0.0001)$ biofilms and $81 \%$ in $24 \mathrm{~h}(\mathrm{p}<0.0001)$ biofilms, when compared with planktonic counterparts. Furthermore, a significant increase in $\mathrm{CSH}$ was found in isolates with $\mathrm{HBF}$ between early $(4 \mathrm{~h})$ and mature $(24 \mathrm{~h})$ phases of biofilm development, where hydrophobicity increased by $31 \%$ ( $\mathrm{p}<$ 0.001). When the hydrophobicity of LBF and HBF was compared, $\mathrm{CSH}$ was significantly increased by $41 \%$ in $\mathrm{HBF}$ isolates at $24 \mathrm{~h}(\mathrm{p}<0.0001)$; however, no significant difference was observed between isolates with LBF and HBF in planktonic cells and $4 \mathrm{~h}$ biofilms.

Amphotericin B activity is impacted by biofilm phenotype Sessile antifungal testing was performed on $C$. albicans isolates with $\mathrm{LBF}$ and $\mathrm{HBF}$ to determine if one group were more susceptible to VRZ or AMB treatment. VRZ was ineffective against all biofilms tested, showing no difference in activity against LBF and HBF (data not shown). However, a dose-dependent effect was evident in all isolates tested with AMB (Figure 3). Moreover, a 

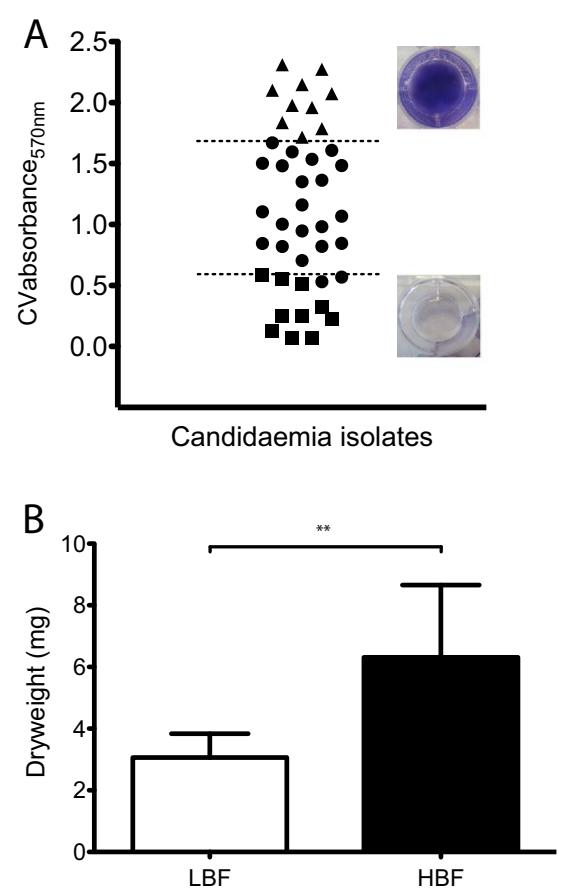

C

i

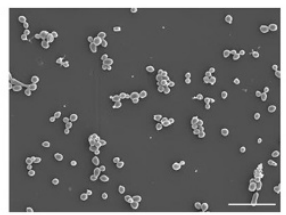

iii

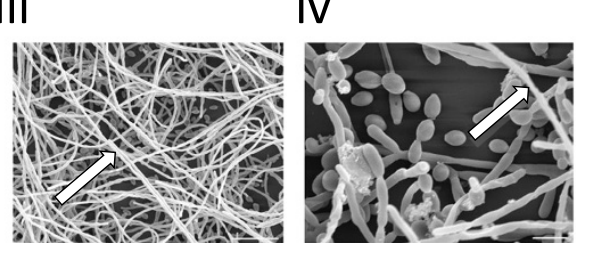

ii

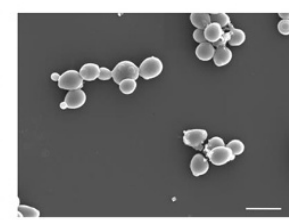

iv

Figure 1 Candida albicans clinical isolates vary in their ability to form biofilms. Forty-two C. albicans bloodstream isolates were used to evaluate biofilm formation of strains derived from a clinical setting. (A) Standardised C. albicans $\left(1 \times 10^{6}\right.$ cells $\left./ \mathrm{mL}\right)$ in RPMI-1640 were grown in flat-bottomed 96 well microtitre plates for $24 \mathrm{~h}$ at $37^{\circ} \mathrm{C}$. Mature biofilms were carefully washed with PBS, allowed to air dry and biomass quantified by staining with $0.05 \% \mathrm{w} / \mathrm{V}$ crystal violet solution. The biofilms were washed and destained with $100 \%$ ethanol. Biomass was quantified spectrophotometrically by reading absorbance at $570 \mathrm{~nm}$ in a microtitre plate reader (FluoStar Omega, BMG Labtech). Eight replicates were used for each isolate and was carried out on two separate occasions, with the mean of each represented. C. albicans LBF (square), HBF (triangle) and IBF (circle) were defined by the upper and lower quartiles, as shown by crystal violet stained biofilms. (B) Three C. albicans LBF and HBF were standardised $\left(1 \times 10^{6}\right.$ cells $\left./ \mathrm{mL}\right)$ in RPMl-1640 and grown in 12 well plates for $24 \mathrm{~h}$ at $37^{\circ} \mathrm{C}$. Biofilms were washed with PBS, biomass scraped and passed through $0.22 \mu \mathrm{m}$ filters before the filters containing the biofilms were dried at $37^{\circ} \mathrm{C}$ for $24 \mathrm{~h}$. Biofilm dry weight was then measured for LBF and HBF, in triplicate on three separate occasions. Data represents mean \pm SD with significance ${ }^{* *} p<0.005$. (C) One C. albicans LBF (i, ii) and HBF (iii, iv) were grown on Thermanox ${ }^{\text {TM }}$ coverslips for $24 \mathrm{~h}$ at $37^{\circ} \mathrm{C}$. Biofilms were then processed and viewed on a JEOL JSM-6400 scanning electron microscope and images assembled using Photoshop software. Note the lack of biomass and hyphal cells in LBF. Scale bars represent $20 \mu \mathrm{m}$ and $5 \mu \mathrm{m}$ for 1000× (i, iii) and 3000× (ii, iv) magnifications, respectively.

significant difference was observed between $\mathrm{LBF}$ and HBF treated with $0.25-32 \mathrm{mg} / \mathrm{L}$ AMB $(\mathrm{p}<0.05)$. LBF and $\mathrm{HBF}$ isolates both had a $\mathrm{MIC}_{50}$ of $0.25 \mathrm{mg} / \mathrm{L} \mathrm{AMB}$, yet isolates with $\mathrm{LBF}$ were significantly less viable than those with $\mathrm{HBF}$ at this concentration $(\mathrm{p}=0.0307)$. In addition, LBF isolates achieved an $\sim 80 \%$ kill at $4 \mathrm{mg} / \mathrm{L}$, whereas $\mathrm{HBF}$ required $32 \mathrm{mg} / \mathrm{L}$ to reach the same kill. No significant differences were observed in the growth rates of either set of LBF and HBF isolates (data not shown).

\section{In vivo pathogenicity is affected by biofilm phenotype}

We next analysed the impact of the isolates ability to form biofilms based upon the severity of infection using a previously described G. mellonella model. The average rate of killing by three $\mathrm{HBF}$, three $\mathrm{LBF}$ and a reference strain (SC5314) of C. albicans were calculated to plot a survival curve. Survival data showed a significant difference in the killing of larvae between HBF and LBF $(\mathrm{p}<0.0001$ [Figure 4A]). After 2 and 6 days, respectively, $>50 \%$ and
$100 \%$ larval death was recorded for HBF isolates, whereas larvae infected with LBF only achieved 20\% killing after 7 days challenge. The reference strain SC5314 achieved $50 \%$ and $100 \%$ larval death by day 4 and 7 , respectively. Similar kill rates to that of HBF were observed in the type strain however, when compared to LBF there was a significant difference in larval mortality $(\mathrm{p}=0.0005)$.

Host-pathogen interactions in this model were then investigated by microscopically observing the morphology of the infected larvae at 24,48 and 72 h postinfection with C. albicans $\mathrm{HBF}$ and LBF (Figure 4B). At $24 \mathrm{~h}$ in both the LBF (Figure 4Bi) and HBF (Figure 4Biv), the nodule formation and melanin deposition were mainly observed under the cuticle and in the fat body, with mild to strong melanisation observed in the centre of the nodules, together with the presence of yeast cells and/or hyphae. The LBF nodules were smaller in dimension and dispersed mainly in the subcuticle area (Figure 4Bi), whereas the HBF nodules had a stronger melanisation with the tendency to converge in large aggregates, and were 


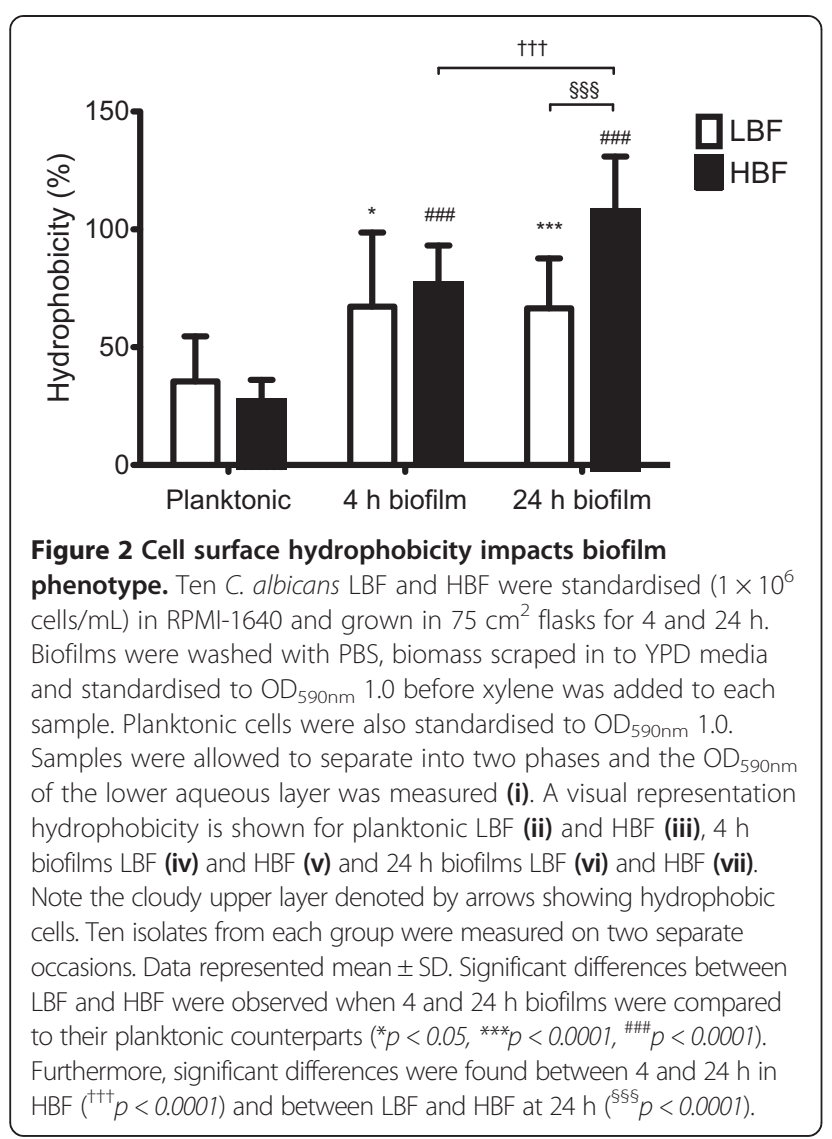

localised more deeply within the fat body (Figure 4Biv). At $48 \mathrm{~h}$, the LBF were confined to the external part of the visceral organs, with a spot-like distribution (Figure 4Bii); whereas the HBF were found to display a pronounced filamentation all around the intestinal wall, with a PAS positive matrix visible surrounding the hyphae (Figure 4Bv). Furthermore at $72 \mathrm{~h}$, there was a substantial invasion of both the gastrointestinal tract and the tracheal system with damaged gut epithelium, where yeast and hyphal cells both observed in the HBF infection (Figure 4Bvi). In contrast, a segmental invasion of the intestinal wall (Figure 4Biii) was observed with LBF infection and the progression of the infection was to a lesser extent than that by the HBF. Table 1 summarises the localisation and characterisation of the nodules with LBF and HBF infected larvae. Changes in the fat body morphology and composition including vacuolisation and haemocyte recruitment, were detected during the course of the infection and were more evident in the HBF.

\section{Transcriptional heterogeneity is associated with biofilm phenotype}

C. albicans clinical isolates defined as $\mathrm{LBF}$ and $\mathrm{HBF}$ were further assessed at a transcriptional level and the expression of genes related to biofilm formation was investigated. $A C T 1$ was used as the housekeeping gene and was shown to be stably expressed throughout all biofilm conditions. Figure 5 illustrates the levels of gene expression of LBF $(\mathrm{n}=10)$ versus $\operatorname{HBF}(\mathrm{n}=10)$ at both $(\mathrm{A}) 4$ and $(\mathrm{B}) 24 \mathrm{~h}$. Overall, the majority of the genes tested followed a trend of up-regulation in HBF compared to LBF. However,

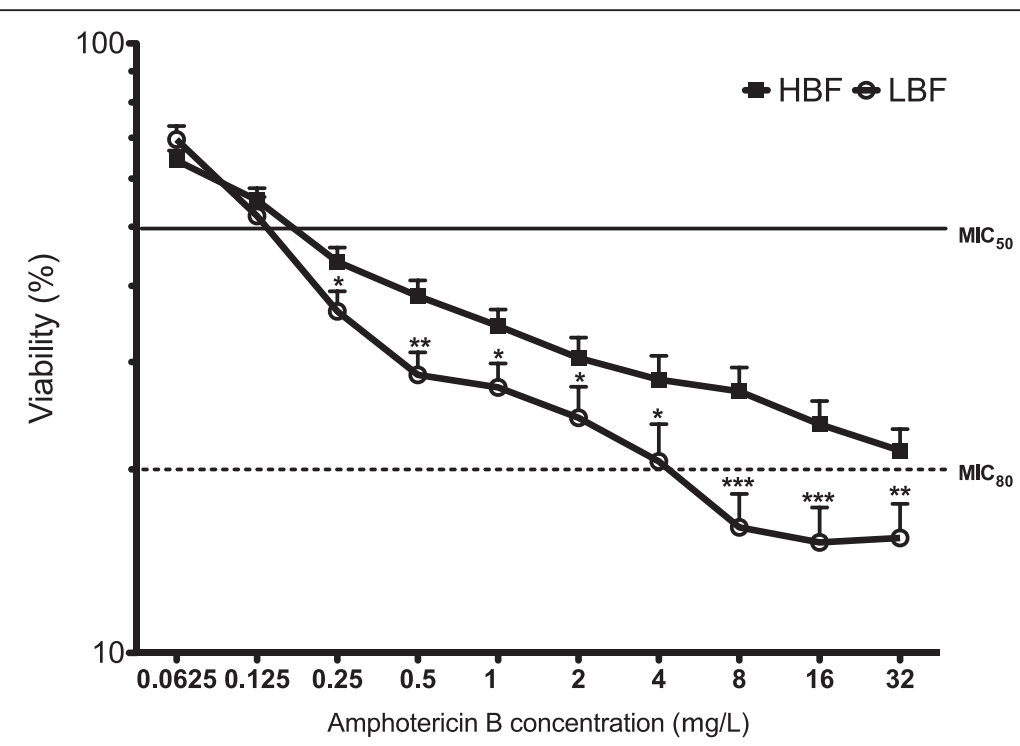

Figure 3 Amphotericin B sensitivity is significantly impacted by biofilm formation. Ten isolates with LBF and HBF were standardised to $1 \times 10^{6} \mathrm{cells} / \mathrm{mL}$ in RPMI-1640 and grown as biofilms in flat-bottomed 96 well microtitre plates for $24 \mathrm{~h}$. Biofilms were washed with PBS before treated with 2 fold serial dilutions of amphotericin B for $24 \mathrm{~h}$. Biofilms were washed and metabolic activity measured using the XTT metabolic assay with absorbance read at $492 \mathrm{~nm}$. Each isolate was tested in duplicate, on three separate occasions with data represented by mean \pm SEM. ${ }^{*} p<0.05,{ }^{* *} p<0.01,{ }^{* *} p<0.001$. 


\section{A}

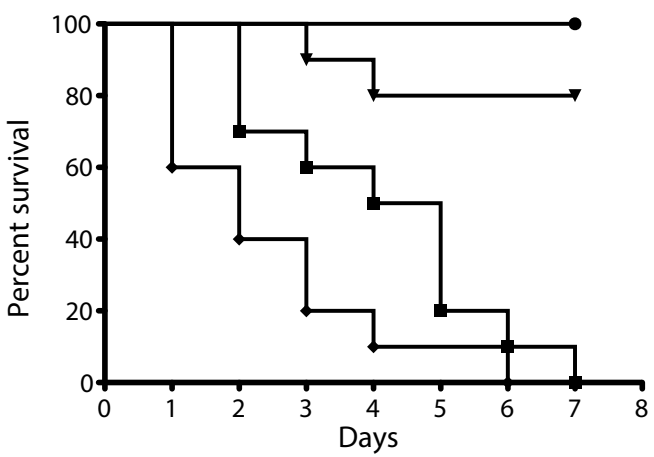

- PBS

- SC5314

$\rightarrow$ HBF

$*$ LBF

B

$24 \mathrm{~h}$

$48 \mathrm{~h}$
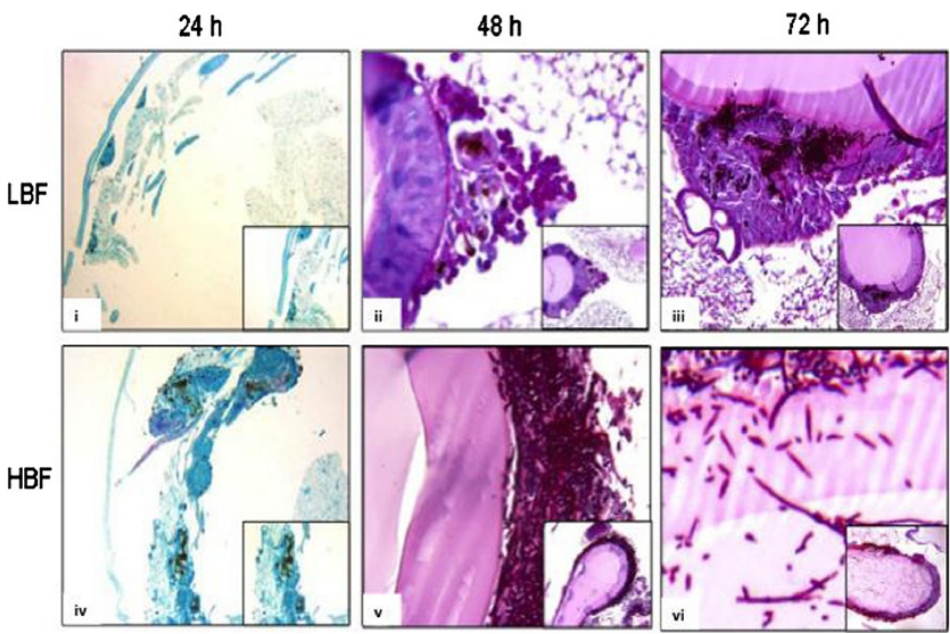

Figure 4 C. albicans HBF have a significant impact on morbidity and mortality rate in vivo. Larvae of G. mellonella were infected with C. albicans LBF or HBF at $1 \times 10^{5} \mathrm{CFU} /$ larva and monitored over a period of 7 days (A). Kaplan-Meier plots of G. mellonella survival after injection of C. albicans demonstrated a strain dependant variation in pathogenicity in vivo. Groups of HBF and LBF clinical isolates were compared to each other and to the SC5314 type strain. The HBF isolates resulted in higher killing rate compared to LBF and SC5314. In contrast, LBF isolates exhibit a slower rate of kill and 100\% mortality did not occur within 7 days. PBS injected larvae were included as a negative control. (B) Infected larvae were formalin fixed and sectioned for histology analysis. At 24 h, LBF infected larvae (i) had several melanisation spots and nodules were present mainly under the cuticle and in the peripheral fat body (Feulgen staining, 20x original magnification (o.m.); inset: $4 \times$ o.m.), whereas HBF infected larvae (iv) had larger nodules with a greater melanin deposition characterised by the recruitment in the external layers of a huge number of haemocytes (20x o.m.; inset: 10× o.m). At 48 h, LBF (ii) small nodules containing both yeast and some hyphae were observed deeper in the larval tissues, sometimes reaching the external part of the gut wall (PAS staining, 20× o.m.; inset: 10× o.m), with HBF (v) having elongated hyphae targeting the intestinal walls (PAS staining, 40× o.m.; inset: 10× o.m.) At 72 h, LBF (iii) showed segmental invasion of the gut walls (PAS staining, 20x o.m.; inset: 10X o.m.) however, HBF (vi) displayed hyphae endoluminal invasion after breaching the intestinal wall (PAS staining, 40× o.m.; inset: $10 \times$ o.m.) with few yeast cells.

Table 1 Characteristics and localisation of nodules found in infected G. mellonella larvae

\begin{tabular}{|c|c|c|c|c|c|c|c|c|c|c|}
\hline & \multicolumn{10}{|c|}{ Nodules } \\
\hline & \multirow[t]{2}{*}{ Size } & \multirow[t]{2}{*}{ Melanisation } & \multirow[t]{2}{*}{ Encapsulation } & \multirow[t]{2}{*}{ Confluence } & \multicolumn{2}{|c|}{ Fungal morphology } & \multicolumn{4}{|c|}{ Localisation } \\
\hline & & & & & Yeast cells & Hyphae & $\mathrm{SC}$ & $\mathrm{FB}$ & $\mathrm{Pl}$ & PT \\
\hline LBF & Small & + & + & - & +++ & $+^{*}$ & + & + & ++ & - \\
\hline HBF & Large &,+++++ & +++ & + & + & $+++^{* *}$ & ++ & ++ & +++ & + \\
\hline
\end{tabular}

SC: subcuticle, FB: fat body, PI: paraintestinal, PT: paratracheal.

*short squat hyphae, ${ }^{* *}$ long tangled hyphae often embedded in an extracellular matrix. 

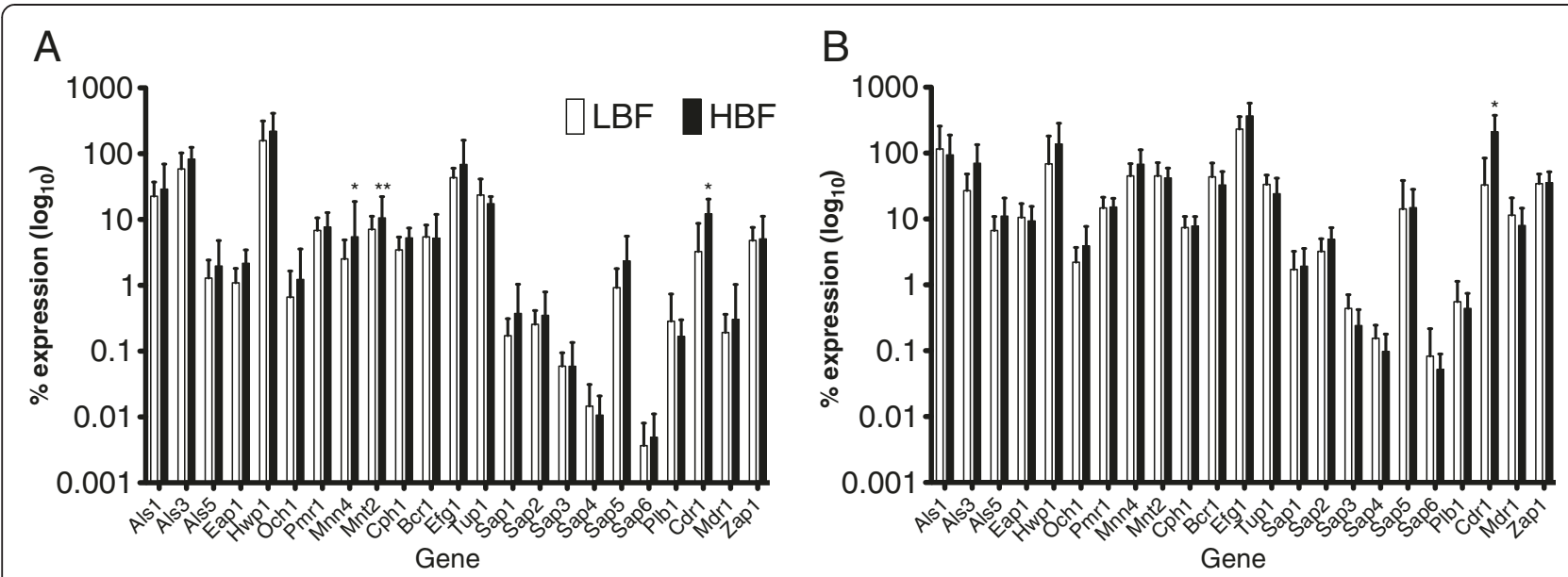

Figure 5 Genes associated with $C$. albicans biofilm development are up-regulated in HBF. Ten C. albicans isolates with LBF and HBF were standardised to $1 \times 10^{6} \mathrm{cells} / \mathrm{mL}$ in RPMl-1640 and grown as biofilms in 24 well microtitre plates for 4 (A) and $24 \mathrm{~h}$ (B) at $37^{\circ} \mathrm{C}$. Biofilms were washed with PBS and RNA extracted using the TRIzol method, CDNA synthesised and real-time PCR used to measure the expression of genes related to $C$. albicans biofilm formation. Percentage of gene expression is shown as $\log _{10}$ mean $\pm \mathrm{SD}$, relative to housekeeping gene $A C T 1$. All strains were assessed in duplicate and included appropriate no RT and non-template controls. ${ }^{*} p<0.05,{ }^{* *} p<0.005$.

statistically significant differences were observed in the glycosylated mannoproteins MNN4 ( $\mathrm{p}=0.0313)$ and MNT2 $(\mathrm{p}=0.0044)$ at $4 \mathrm{~h}$, where expression was increased by $\sim 2$ fold. Furthermore, the resistance gene CDR1 was significantly increased in HBF by 4 - and 6-fold at $4 \mathrm{~h}$ $(\mathrm{p}=0.0113)$ and $24 \mathrm{~h}(\mathrm{p}=0.0239)$, respectively (Additional file 2: Table S1).

Clustering the expression of 23 selected genes from 5 different functional groups in a heat map showed their relationship with one another and their variable expression in LBF and HBF over time (Figure 6). Here we found the adhesion genes ALS3 and HWP1 were closely related and highly expressed, particularly in HBF isolates at 4 and $24 \mathrm{~h}$. Furthermore, genes from different functional groups were closely related to one another irrespective of whether LBF or HBF, such as the proteinase SAP5 and the adhesion genes $A L S 5$ and EAP1. The remaining SAP genes were all closely related to one another, and interestingly the resistance gene $M D R 1$ and the cell wall mannoprotein OCH1. Further analysis of SAP3 showed an increase in transcription within LBF at $24 \mathrm{~h}$, despite no differences being observed at $4 \mathrm{~h}$. In contrast, SAP5 expression was consistently high at 4 and $24 \mathrm{~h}$ within HBF.

Analysis of Spearman rho coefficients found that out of 23 selected genes, 7 including those related to adhesion (ALS3, EAP1), filamentation (CPH1), hydrolytic enzymes (SAP5, PLB1) and resistance (CDR1 and ZAP1) showed a significant positive correlation $(\mathrm{p}<0.05)$ with $\mathrm{cv}$ biomass data at $4 \mathrm{~h}$ (Table 2). Further analysis of the relationship between these seven genes and all the other genes tested presented various correlations (marked bold in Table 2). For example, PLB1 was significantly correlated with all other genes tested (94.11\%) except ZAP1, followed by CPH1 (76.47\%), SAP5 (76.47\%), EAP1 (64.71\%), CDR1 (41.17\%), ALS3 (35.29\%) and ZAP1 (11.76\%). Correlation of individual genes with one another at the $4 \mathrm{~h}$ time point showed that PLB1, CPH1, MNN4 and HWP1 all correlated with 5 of the 7 key genes defined above. Notably, 24 h gene expression revealed very few significant correlations other than cv. In fact, a significant negative correlation was found between SAP3 and the biomass data (Rho $=-0.465, \mathrm{p}=0.045$ ). Furthermore, SAP3 was positively correlated with $M N T 2$ ( $\mathrm{Rho}=0.468$, $\mathrm{p}=0.043)$ and SAP4 (Rho $=0.460, \mathrm{p}=0.048)$.

\section{Discussion}

C. albicans is an important pathogen. It is the fourth most common organism isolated from total bloodstream infections [2] and continues to carry a high mortality. The presence of medical devices such as central venous catheters (CVC's) are known to be important risk factors [14] suggesting that biofilm formation is a key feature in the pathogenesis of candidaemia. The past decade has seen a significant leap in our knowledge and understanding of the biology of $C$. albicans biofilms, particularly with respect to the molecular basis of their development and homeostasis [15]. However, in the clinical setting it is generally assumed that all $C$. albicans isolates have the capacity to form biofilms, but often with little regard to individual differences within the species when managing the infection. Here we demonstrate that $C$. albicans display heterogeneous biofilm characteristics, and these strain differences have important implications with respect to treatment and pathogenicity.

Previous studies have reported very defined categories in their analysis of association with clinical outcomes, i.e. 


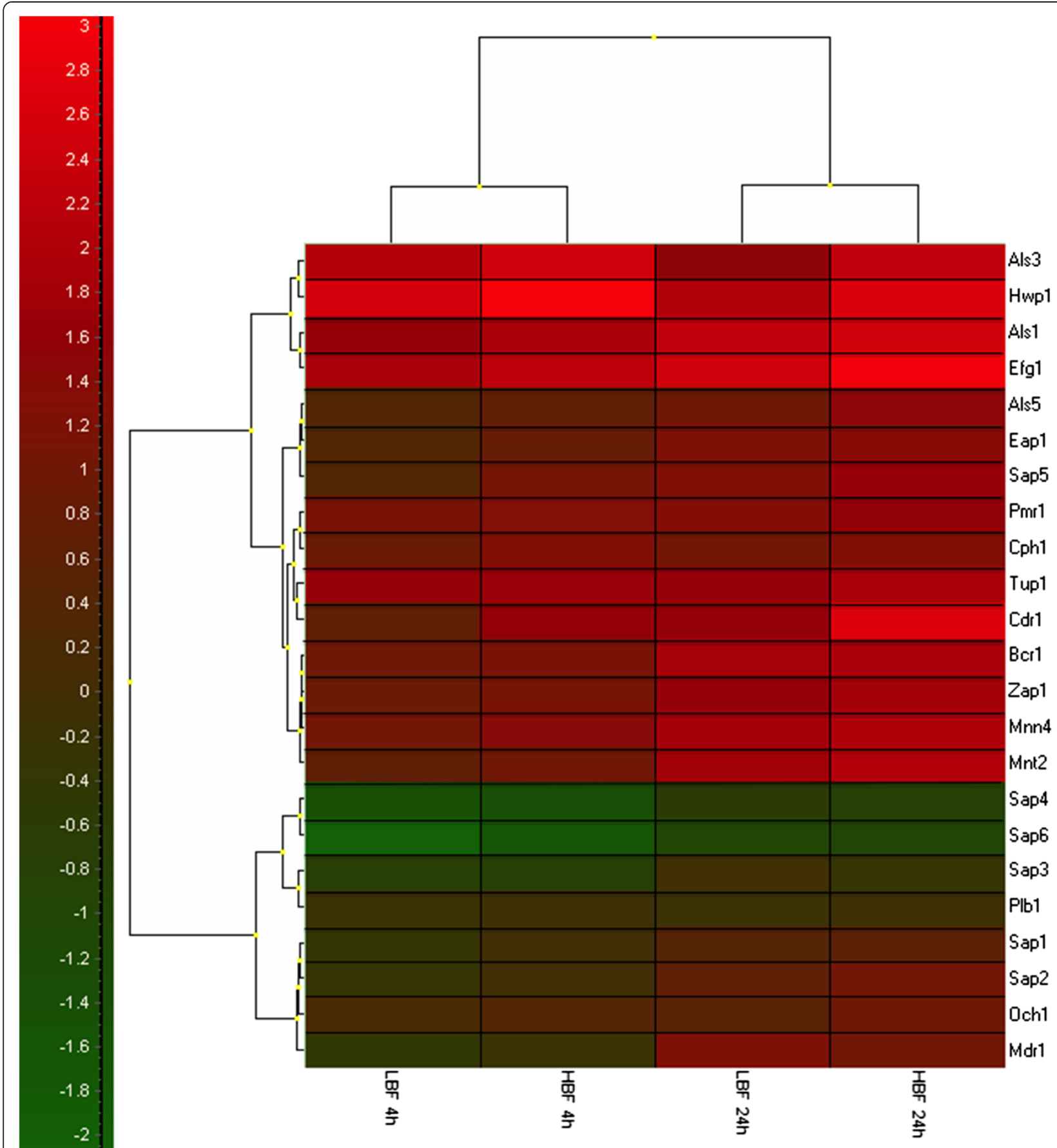

Figure 6 Clustering analysis identified the transcriptional relationship of biofilm specific genes. Percentage expression of each gene was also assessed by clustering and heat map analysis using GenEx software. Data was log transformed and mean values were used for heat map construction. Increased expression of genes is shown by red and a decrease is represented by green.

biofilm formers and non-biofilm formers $[8,16]$. However, these important studies fail to take into account the heterogeneous nature of individual clinical isolates forming biofilms, which based on their metabolic XTT values can range from 0.125 to 1.358 [16]. When looking for clinical correlations with these phenotypes then important information can be missed, as the isolates at either end of the biofilm forming spectrum may lead to different clinical outcomes. We therefore aimed to evaluate and categorise $C$. albicans biofilms into distinct levels of biofilm formation to determine if their biological features were significantly different. Initially we categorised biofilms grown in RPMI using a biomass stain [17] and followed this up with dry weight analysis, which differentiated clinical isolates into 
Table 2 C albicans biomass correlates with biofilm-related gene expression

\begin{tabular}{|c|c|c|c|c|c|c|c|c|}
\hline \multicolumn{2}{|c|}{$4 \mathrm{~h}$ Correlations $\mathrm{a}^{\mathrm{a}}$} & \multirow{2}{*}{$\frac{A L S 3}{.529^{*}}$} & \multirow{2}{*}{$\begin{array}{l}\text { EAP1 } \\
.608^{* *}\end{array}$} & \multirow{2}{*}{$\begin{array}{l}\text { CPH1 } \\
.534^{*}\end{array}$} & \multirow{2}{*}{$\frac{\text { SAP5 }}{.539^{*}}$} & \multirow{2}{*}{$\frac{P L B 1}{.483^{*}}$} & \multirow{2}{*}{$\frac{C D R 1}{.647^{* *}}$} & \multirow{2}{*}{$\begin{array}{l}\text { ZAP1 } \\
.515\end{array}$} \\
\hline$\overline{C V}$ & Rho $=$ & & & & & & & \\
\hline & $p=$ & .029 & .010 & .027 & .026 & .050 & .005 & .035 \\
\hline \multirow[t]{2}{*}{$A L S 1$} & Rho $=$ & .240 & $.529^{*}$ & $.542^{*}$ & .336 & $.608^{* *}$ & .382 & .250 \\
\hline & $p=$ & .353 & .029 & .025 & .188 & .010 & .130 & .333 \\
\hline \multirow[t]{2}{*}{ ALS3 } & Rho $=$ & 1.000 & .385 & $.708^{* *}$ & $.544^{*}$ & $.593^{*}$ & $.779^{* *}$ & .365 \\
\hline & $p=$ & & .127 & .001 & .024 & .012 & .000 & .149 \\
\hline \multirow[t]{2}{*}{ ALS5 } & Rho $=$ & .229 & $.538^{*}$ & $.644^{* *}$ & $.607^{* *}$ & $.681^{* *}$ & .145 & .214 \\
\hline & $p=$ & .378 & .026 & .005 & .010 & .003 & .579 & .410 \\
\hline \multirow[t]{2}{*}{ EAP1 } & Rho $=$ & .385 & 1.000 & $.544^{*}$ & $.490^{*}$ & $.860^{* *}$ & $.537^{*}$ & .279 \\
\hline & $p=$ & .127 & & .024 & .046 & .000 & .026 & .277 \\
\hline \multirow[t]{2}{*}{ HWP1 } & Rho $=$ & $.868^{* *}$ & .338 & $.821^{* *}$ & $.571^{*}$ & $.532^{*}$ & $.615^{* *}$ & .201 \\
\hline & $p=$ & .000 & .184 & .000 & .017 & .028 & .009 & .439 \\
\hline \multirow[t]{2}{*}{ MNN4 } & Rho $=$ & .350 & $.554^{*}$ & $.645^{* *}$ & $.537^{*}$ & $.672^{* *}$ & $.493^{*}$ & .309 \\
\hline & $p=$ & .168 & .021 & .005 & .026 & .003 & .045 & .228 \\
\hline \multirow[t]{2}{*}{ PMR1 } & Rho $=$ & .333 & $.635^{* *}$ & $.527^{*}$ & $.534^{*}$ & $.784^{* *}$ & .233 & .377 \\
\hline & $p=$ & .191 & .006 & .030 & .027 & .000 & .368 & .135 \\
\hline \multirow[t]{2}{*}{$B C R 1$} & Rho $=$ & .262 & .250 & $.539^{*}$ & $.566^{*}$ & $.485^{*}$ & .306 & $.522^{*}$ \\
\hline & $p=$ & .309 & .333 & .026 & .018 & .048 & .232 & .032 \\
\hline \multirow[t]{2}{*}{$\mathrm{CPHI}$} & Rho $=$ & $.708^{* *}$ & $.544^{*}$ & 1.000 & $.833^{* *}$ & $.748^{* *}$ & $.547^{*}$ & .321 \\
\hline & $p=$ & .001 & .024 & & .000 & .001 & .023 & .209 \\
\hline \multirow[t]{2}{*}{ EFG1 } & Rho $=$ & .257 & $.520^{*}$ & $.576^{*}$ & $.645^{* *}$ & $.605^{*}$ & .409 & .392 \\
\hline & $p=$ & .319 & .033 & .016 & .005 & .010 & .103 & .119 \\
\hline \multirow[t]{2}{*}{ TUP1 } & Rho $=$ & $.713^{* *}$ & .397 & .397 & .463 & $.544^{*}$ & $.684^{* *}$ & .444 \\
\hline & $p=$ & .001 & .115 & .115 & .061 & .024 & .002 & .074 \\
\hline \multirow[t]{2}{*}{ SAP1 } & Rho $=$ & .356 & $.523^{*}$ & $.794^{* *}$ & $.744^{* *}$ & $.730^{* *}$ & .251 & .413 \\
\hline & $p=$ & .160 & .031 & .000 & .001 & .001 & .332 & .100 \\
\hline \multirow[t]{2}{*}{ SAP2 } & Rho $=$ & .091 & $.554^{*}$ & .478 & .417 & $.654^{* *}$ & .172 & .292 \\
\hline & $p=$ & .729 & .021 & .052 & .096 & .004 & .510 & .256 \\
\hline \multirow[t]{2}{*}{ SAP5 } & Rho $=$ & $.544^{*}$ & $.490^{*}$ & $.833^{* *}$ & 1.000 & $.676^{* *}$ & .395 & $.539^{*}$ \\
\hline & $p=$ & .024 & .046 & .000 & & .003 & .117 & .026 \\
\hline \multirow[t]{2}{*}{ SAPG } & Rho $=$ & .371 & $.772^{* *}$ & $.637^{* *}$ & $.627^{* *}$ & $.869^{* *}$ & .320 & .284 \\
\hline & $p=$ & .143 & .000 & .006 & .007 & .000 & .211 & .269 \\
\hline \multirow[t]{2}{*}{$P L B 1$} & Rho $=$ & $.593^{*}$ & $.860^{* *}$ & $.748^{* *}$ & $.676^{* *}$ & 1.000 & $.532^{*}$ & .434 \\
\hline & $p=$ & .012 & .000 & .001 & .003 & & .028 & .082 \\
\hline \multirow[t]{2}{*}{ CDR1 } & Rho $=$ & $.779^{* *}$ & $.537^{*}$ & $.547^{*}$ & .395 & $.532^{*}$ & 1.000 & .262 \\
\hline & $p=$ & .000 & .026 & .023 & .117 & .028 & & .309 \\
\hline ZAP1 & Rho $=$ & .365 & .279 & .321 & $.539^{*}$ & .434 & .262 & 1.000 \\
\hline & $p=$ & .149 & .277 & .209 & .026 & .082 & .309 & \\
\hline
\end{tabular}

*Correlation is significant at the 0.05 level (2-tailed), ** Correlation is significant at the 0.01 level (2-tailed).

a. List wise $\mathrm{N}=17$.

defined groupings. This approach was used in preference to metabolic assays due to the highly variable nature of XTT from strain to strain [16]. Moreover, XTT's mainstay usefulness is limited to antifungal drug testing of biofilms $[11,18]$. Our classification, based initially on biomass, was supported by observations on a macro- and microscopic level where it was clear that numerous cells consisting of hyphae and yeasts were visible in $\mathrm{HBF}$, whereas scant layers of yeast cells were observed for LBF. We also investigated CSH as an additional biofilm positive feature, as previous studies 
have also shown a link between biofilm biomass and CSH $[13,19]$. This study confirms that CSH impacts different phases of biofilm development, which is in agreement with previous work where it was shown that cells dispersed from mature biofilms were more hydrophobic than those dispersed from earlier stages of biofilm development [20]. Furthermore, it has been shown hydrophobic cells are more adherent [21], and therefore it is unsurprising that $\mathrm{CSH}$ was increased in HBF isolates. Based on our overall approach to biofilm categorisation we can be confident in the phenotypes selected for further detailed analysis. We do however concede there are caveats to defining levels of biofilm, and this requires further work and collaboration between groups to establish a standardised method.

One of the key defining features of $C$. albicans biofilms is their insensitivity to sterol active antifungal agents [5]. We examined azole treatment, which unsurprisingly demonstrated poor activity overall with no group differences, presumably through adaptive resistance mechanisms as previously described [22-24]. Notably, AMB was less effective against HBF biofilms than LBF, which we hypothesise is due to the inability of the compound to permeate easily throughout the dense physical structure of the cells encased within ECM [25]. We purposely excluded echinocandins from this study as these have been shown to be an effective anti-biofilm antifungals, therefore quantifying differences in activity against the two populations would be difficult [26]. These observations may have implications to whether a patient responds to antifungal therapy, as Tumbarello and colleagues (2012) demonstrated that inadequate antifungal therapy (azoles) and the presence of an indwelling venous catheter were key predictors of patient mortality and hospital length of stay in patients infected with biofilm forming isolates [8]. Guidelines have also suggested that removal of the catheter is an important factor in improving clinical outcomes, again supporting the notion that biofilm formation has a crucial role in clinical outcomes $[27,28]$. Given the importance of these infections, efficient and appropriate treatment in candidaemia cases has been highlighted [29,30], as failure to treat quickly and effectively has profound consequences on mortality statistics [31].

We decided to test the hypothesis that clinical isolates capable of forming robust biofilms were more pathogenic, which may be a reason for their apparent role in infections with increased mortality [16]. Previous experimental work has shown that cells dispersed from biofilms are more cytotoxic and kill mice quicker than the equivalent planktonic cells [7]. Using a G. mellonella model we showed that HBF isolates caused significantly greater mortality rates than LBF isolates, a finding supported elsewhere [32]. In addition, another study investigated the virulence of $C$. albicans isolates with varying levels of biofilm formation and found that mice infected with a LBF had increased survival rates compared to isolates that were infected with HBF [33]. Histological analysis of the infected larvae displayed similar cell morphology of yeast and filamentous hyphae as observed in SEM images of LBF and HBF, respectively. This is in agreement with a previous study that showed filamentation plays a role in killing G. mellonella larvae [34].

Filamentous growth is a characteristic feature of $C$. albicans biofilm formation. Defective hyphal formation through deletion of EFG1 has been shown to lead to low levels of biofilm growth [35]. Given our growing knowledge of key biofilm related genes we decided to investigate transcriptional changes to determine whether these are truly represented amongst clinical isolates, and therefore could be used as a more robust way to categorise biofilm formation and as potential diagnostic targets of HBF isolates. ACT1, the stably expressed housekeeping gene, as reported elsewhere [36-38], enabled these relative comparisons. Regulation of biofilm related genes were shown to influence an isolates biomass within clinical isolates, echoing work carried out by other groups $[39,40]$. Cluster analysis of the selected biofilm related genes showed a good association with functional classes of genes, such as adhesins and proteinases, suggesting that both LBF and HBF had conserved pathways in the basic developmental phases of biofilm growth. However, individual gene expression profiles were inconclusive, showing very few clear independent significant differences, though gene expression proved interesting at $4 \mathrm{~h}$. We investigated the overall biomass at $24 \mathrm{~h}$ and examined how $4 \mathrm{~h}$ gene expression related to this. Overall HWP1 was the most highly regulated at this time point in both LBF and HBF, as has been shown elsewhere [39], though no significant differences between the populations were observed. Seven other genes were however shown to have significant positive correlations with biomass. The most significant was $C D R 1$, which was unsurprising as it has been shown to be transiently expressed in different biofilm studies, though does not correspond directly to antifungal resistance [41,42]. PLB1 was showed to be significantly correlated with another 16 genes including biomass, though expression appeared constitutively low level within the biofilm, which is agreement with previous studies [39], and may have an accessory role in the degradation of host tissue alongside SAP's. Of these, SAP5 was shown to be highly expressed in mature biofilms, and correlated with biomass and 13 other genes. We previously reported that SAP5 was associated with higher levels of expression in in vitro biofilms formed from denture stomatitis C. albicans isolates [43]. In addition, Nailis and colleagues demonstrated its crucial role both in a reconstituted human epithelial model and within in vivo biofilms [39]. Furthermore, the role of Sap5 in biofilm formation has recently 
been demonstrated in BSI, where its expression was significantly increased when compared to planktonic counterparts [44]. Adhesins, such as ALS3 was also upregulated, which has previously been identified to be involved in biofilm formation, particularly at early stages of biofilm development (0-6 h) [45,46], where C. albicans mutants lacking this gene produce sparse biofilms on catheter material in vitro [47]. EAP1, though showing no clear independent association with biofilm formation per se, did show a clear correlation with biomass and 11 other genes. Its importance in biofilm formation has been reported previously [48]. Of interest was the positive correlation with ZAP1 expression at $4 \mathrm{~h}$, which is a negative regulator of matrix production [49]. It did positively correlate with BCR1, the global regulator of biofilm formation, suggesting that the early interaction between their proteins may be important for downstream construction of the biofilm. Collectively the data highlighted the importance of looking at multiple genes at once opposed to single gene targets.

\section{Conclusions}

Overall, we have categorised isolates based on biological properties relating to biofilm characteristics, and evaluated these in models of infection and treatment, where we have shown clear differences in virulence. In an attempt to create a molecular basis of categorising these strains we have used gene expression studies, and showed that individual gene expression analysis of the biofilm related genes to differentiate and categorise biofilm-forming isolates may be futile. Instead, we have shown that taking a defined panel of genes during early biofilm growth may be more informative. In particular, the panel of genes such as SAP5, HWP1, EAP1, PLB1 and CDR1 investigated in tandem could constitute an important step towards diagnostics of $C$. albicans biofilm formation, though the use of transcriptomics, such as RNA-Seq, may prove useful in identifying novel diagnostic targets. Further work is required to determine why some patients succumb to $C$. albicans biofilms whereas others do not, as the HBF isolates do have an increased pathogenic potential and are more difficult to manage with antifungal agents.

\section{Methods}

\section{Culture conditions and standardisation}

Candida albicans SC5314, 3153A and a series of routine patient anonymised clinical bloodstream isolates $(n=42)$ collected under the approval of the NHS Scotland Caldicott Gaurdians from the Royal Hospital for Sick Children (Yorkhill Division), Glasgow, UK, as part of candidaemia epidemiology surveillance study. All clinical isolates obtained during this period were independently identified using Colorex Candida chromogenic plates (E\&O Laboratories Ltd, Bonnybridge, UK) and were stored in Microbank ${ }^{\circledast}$ vials (Pro-Lab Diagnostics, Cheshire, UK) at $-80^{\circ} \mathrm{C}$ until further use. These isolates were sub-cultured onto Sabouraud's dextrose agar (SAB [Sigma-Aldrich, Dorset, UK]). Plates were incubated at $30^{\circ} \mathrm{C}$ for $48 \mathrm{~h}$ and maintained at $4^{\circ} \mathrm{C}$. Isolates were propagated in yeast peptone dextrose (YPD) medium (Sigma-Aldrich, Dorset, UK), washed by centrifugation and resuspended in the appropriate media (Sigma-Aldrich) to the desired concentration, as described previously [50].

\section{Characterisation of Candida albicans biofilm formation by clinical isolates}

All C. albicans clinical isolates $(\mathrm{n}=42)$ were standardised to $1 \times 10^{6}$ cells $/ \mathrm{mL}$ in RPMI-1640 and biofilms grown in flat-bottomed 96 well microtitre plates at $37^{\circ} \mathrm{C}$ for $24 \mathrm{~h}$ and biomass of each isolate assessed using the crystal violet (cv) assay as previously reported [17], and isolates were grouped based on their level of biomass distribution $\left(\mathrm{OD}_{570 \mathrm{~nm}}\right.$ values). Isolates that fell below the $1^{\text {st }}$ quartile $\left(\mathrm{Q}_{1}\right)$ were classed as having low biofilm formation (LBF), strains with a biomass greater than the $3^{\text {rd }}$ quartile $\left(\mathrm{Q}_{3}\right)$ were deemed isolates with high biofilm formation (HBF), and those that lay in between were classified as intermediate biofilm formation (IBF $\left.\mathrm{Q}_{2}\right)$. C. albicans biomass was further assessed using dry weight measurements. Selected isolates with LBF and HBF were grown as biofilms in 12 well tissue culture plates for $24 \mathrm{~h}$, as previously described, and the resulting biomass homogenised in $1 \mathrm{~mL}$ of PBS using a cell scraper (STARLAB, Milton Keynes, UK). This was then passed through a $0.22 \mu \mathrm{m}$ filter disc (Satorius Stedim) using a vacuum and filters were dried at $40^{\circ} \mathrm{C}$ overnight before measuring each isolates dry weight. Uninoculated controls were used for background correction.

\section{Biofilm visualisation}

Representative isolates were also grown within 12 well flat-bottomed tissue culture plates (Corning Incorporated, NY, USA) for $24 \mathrm{~h}$ before carefully washing with PBS, stained with $\mathrm{cV}$ and then digitally imaged (Canon IXUS $220 \mathrm{HS}$ ). For scanning electron microscopy (SEM) representative $C$. albicans clinical isolates defined as LBF and HBF were grown directly onto Thermanox ${ }^{\mathrm{Tm}}$ coverslips (Nunc, Roskilde, Denmark), then processed and analysed as previously described [51].

\section{Cellular surface hydrophobicity assay}

The cell surface hydrophobicity (CSH) was determined for selected $C$. albicans clinical isolates with LBF $(n=10)$ and $\operatorname{HBF}(\mathrm{n}=10)$. CSH was assessed using the microbial adhesion to hydrocarbon test, with a few modifications [52,53]. Isolates were standardised to $1 \times 10^{6}$ cells $/ \mathrm{mL}$ in RPMI1640 and grown as biofilms for 4 and $24 \mathrm{~h}$ in $75 \mathrm{~cm}^{2}$ flasks (Nunc, Rochester, NY) at $37^{\circ} \mathrm{C}$. These were then washed with PBS and the resultant biomass scraped off and 
homogenised in YPD. Cells were standardised $\left(\mathrm{OD}_{590 \mathrm{~nm}}\right.$ 1.0) and cells transferred into a glass tube and overlaid with $1 / 5^{\text {th }}$ volume of xylene. Contents were vortexed for $1 \mathrm{~min}$ and phases separated over $30 \mathrm{~min}$. The aqueous phase was carefully removed and $\mathrm{OD}_{590 \mathrm{~nm}}$ measured. The percentage of hydrophobicity was calculated as $\left(\left[\mathrm{OD}_{590 \mathrm{~nm}}\right.\right.$ before xylene overlay - $\mathrm{OD}_{590 \mathrm{~nm}}$ after xylene overlay]/ $\mathrm{OD}_{590 \mathrm{~nm}}$ before xylene overlay) $\times 100 \%$.

\section{Antifungal susceptibility testing of biofilms}

Antifungal testing to determine minimum inhibitory concentration (MIC) of sessile cells was performed using voriconazole (VRZ) and amphotericin B (AMB) (SigmaAldrich, Gillingham, UK) on $24 \mathrm{~h}$ preformed biofilms, as previously described in flat-bottomed, 96 well microtitre plates [50]. C. albicans $\operatorname{LBF}(\mathrm{n}=10)$ and $\operatorname{HBF}(\mathrm{n}=10)$ were tested in duplicate, on three separate occasions. Sessile minimum inhibitory concentrations (SMICs) were determined at $80 \%$ inhibition using an XTT (2,3-bis(2methoxy-4-nitro-5-sulfo-phenyl)-2H-tetrazolium-5-caboxanilide) metabolic reduction assay [11].

\section{Galleria mellonella pathogenicity assay}

The pathogenicity of C. albicans isolates pre-defined as $\operatorname{LBF}(\mathrm{n}=3)$ and $\operatorname{HBF}(\mathrm{n}=3)$ were assessed using the $G$. mellonella killing assay, as described previously [54]. This biological model has been shown previously to be useful in the study of fungal virulence $[32,55,56]$. Sixthinstar G. mellonella larvae (Livefoods Direct Ltd, UK) were stored in the dark and used within 7 days of shipment. Ten random larvae with a bodyweight of between 200 to $300 \mathrm{mg}$ were used for each group. Overnight YPD cultures of each isolate were washed and standardised to $1 \times 10^{7}$ cells $/ \mathrm{mL}$ in PBS. Larvae were inoculated using a $50-\mu$ l Hamilton syringe with $26 \mathrm{~g}$ needle by injecting $10 \mu \mathrm{L}$ aliquots $\left(1 \times 10^{5}\right.$ cells/larva $)$ into the haemocoel, through the hindmost proleg. In addition, mock inoculated larvae pierced on the proleg with a sterile needle and a PBS inoculated control group were also included in each experiment. The infected larvae were placed in sterile petri dishes, incubated at $37^{\circ} \mathrm{C}$ and the number of dead larvae were scored daily. Larva was considered dead when it displayed no movement in response to touch together with a dark discolouration of the cuticle. Pathogenicity of LBF and HBF was assessed using a Kaplan-Meier plot with percentage survival monitored over 7 days.

\section{Histology analysis of infected Galleria mellonella}

The morphology of the larvae infected with two isolates of C. albicans LBF and HBF was examined. Larvae were infected with the respective strains as described previously, and after post-infection (24, 48 and $72 \mathrm{~h}$ ) larvae were fixed by a direct injection of formalin into the haemocoel and by
Table 3 Candida albicans primers for real time qPCR

\begin{tabular}{|c|c|}
\hline Gene & Sequence $\left(5^{\prime}-3^{\prime}\right)$ \\
\hline \multirow[t]{2}{*}{ ALS1 } & F - TTCTCATGAATCAGCATCCACAA \\
\hline & R - CAGAATTTCACCCATACTTGGTTTC \\
\hline \multirow[t]{2}{*}{ ALS3 } & F - CAACTTGGGTTATTGAAACAAAAACA \\
\hline & R - AGAAACAGAAACCCAAGAACAACCT \\
\hline \multirow[t]{2}{*}{ ALS5 } & F - CTGCCGGTTATCGTCCATTTA \\
\hline & R - ATTGATACTGGTTATTATCTGAGGGAGAAA \\
\hline \multirow[t]{2}{*}{ EAP1 } & F - ACCACCACCGGGTATACAAA \\
\hline & R - GCCATCACATTTGGTGACAG \\
\hline \multirow[t]{2}{*}{ HWP1 } & F - GCTCAACTTATTGCTATCGCTTATTACA \\
\hline & R - GACCGTCTACCTGTGGGACAGT \\
\hline \multirow[t]{2}{*}{$B C R 1$} & F - ATTGCCACCAATACCTGCTC \\
\hline & R - GGCTGTCCATGTTGTTGTTG \\
\hline \multirow[t]{2}{*}{$\mathrm{CPH} 1$} & F - ACGCAGCCACAAGCTCTACT \\
\hline & R - GTTGTGTGTGGAGGTTGCAC \\
\hline \multirow[t]{2}{*}{ EFG1 } & F - CCAGTGGTGGCAGTAATGTG \\
\hline & R - CAGTGGCAGCCTTGGTATTT \\
\hline \multirow[t]{2}{*}{ TUP1 } & F - GCTTCAGGTAACCCATTGTTGAT \\
\hline & R - CTTCGGTTCCCTTTGAGTTTAGG \\
\hline \multirow[t]{2}{*}{$\mathrm{OCH} 1$} & F - TCATCCAATGTTGCGTGAAT \\
\hline & R - TCATGATATCGCCACCTTCA \\
\hline \multirow[t]{2}{*}{ PMR1 } & F - GAATCCCCGCAGACATTAGA \\
\hline & R - GGGCCTGTITTCACCAGTTA \\
\hline \multirow[t]{2}{*}{ MNN4 } & F - TGAGCAATCGTCAAAACCAG \\
\hline & R - GGCGGTTGTCATTTGTTGAT \\
\hline \multirow[t]{2}{*}{ MNT2 } & F - CGTCAAGGTGCCTGAAGAAT \\
\hline & R - GAGGAGGAGGAGGATTTTGG \\
\hline \multirow[t]{2}{*}{$C D R 1$} & F - GTACTATCCATCAACCATCAGCACTT \\
\hline & R - GCCGTTCTTCCACCTITTTGTA \\
\hline \multirow[t]{2}{*}{ MDR1 } & F - TCAGTCCGATGTCAGAAAATGC \\
\hline & R - GCAGTGGGAATTTGTAGTATGACAA \\
\hline \multirow[t]{2}{*}{ ZAP1 } & F - CGACTACAAACCACCAGCTTCATC \\
\hline & R - CCCCTGTTGCTCATGTTTTGT \\
\hline \multirow[t]{2}{*}{$A C T 1$} & F - AAGAATTGATTTGGCTGGTAGAGA \\
\hline & R - TGGCAGAAGATTGAGAAGAAGTTा \\
\hline
\end{tabular}

formalin immersion at room temperature for $24 \mathrm{~h}$. Paraffin embedded samples were then transversally sectioned into four-micron thickness using a microtome (microm HM $3335 \mathrm{H}$, Thermoscientific). Sections were then stained with Periodic Acid-Schiff (PAS) to evaluate $C$. albicans infected cells. Whole larvae sections were examined for characterisation and localisation of nodules by light optical microscope visualisation (Leica microscope, model 020-519.502). Two larvae were processed for each isolate, carried out on three separate occasions. 


\section{Transcriptional analysis of biofilm related genes}

C. albicans clinical isolates exhibiting $\operatorname{LBF}(\mathrm{n}=10)$ and HBF $(n=10)$ were selected for the analysis of genes related to biofilm formation [57]. Biofilms were grown in 24 well flat-bottomed plates for 4 and $24 \mathrm{~h}$ at $37^{\circ} \mathrm{C}$, as described above. Following incubation, biofilms were washed with PBS, removed and homogenised using a bead beater, and RNA extracted using the TRIzol ${ }^{\mathrm{TM}}$ (Life Technologies, Paisley, UK) method as described previously by our group [42]. Total RNA was DNase (Qiagen, Crawley, UK) treated and purified using an RNeasy MinElute clean up kit (Qiagen, Crawley, UK), as per manufacturer's instructions. RNA was quantified and quality assessed using a NanoDrop spectrophotometer (ND-1000, ThermoScientific, Loughborough, UK). Next, cDNA was synthesised from 200 ng of total RNA using High Capacity RNA to cDNA kit (Life Technologies, Paisley, UK) in a MyCycler PCR machine (Bio-Rad Laboratories, Hertfordshire, UK), following manufacturers instructions.

All primers utilised for this study for quantitative PCR (qPCR) were designed from their sequences obtained from the Candida Genome Database (CGD) website (http://www.candidagenome.org). The web-based primer design software program Primer3 (http://primer3.ut.ee/) was used. Primers were checked for specificity to $C$. albicans using the NIH-BLAST for short or exact nucleotide sequences (http://blast.ncbi.nlm.nih.gov/Blast.cgi). PCR amplification efficiencies of all designed primer sets were optimised prior to gene expression analysis, with efficiencies of $90-110 \%$ used in this study. Details of the oligonucleotides primers (Eurogentec, Southampton, UK) used in this study are listed in Table 3. 200 ng cDNA was used in a mastermix containing $\mathrm{SYBR}^{\ominus}$ GreenER $^{\mathrm{TM}}$ (Life Technologies, Paisley, UK), UV-treated RNase-free water and forward/reverse primers $(10 \mu \mathrm{M})$, following manufacturers' instructions. Cycle conditions consisted of $2 \mathrm{~min}$ at $50^{\circ} \mathrm{C}, 10 \mathrm{~min}$ at $95^{\circ} \mathrm{C}$ and forty cycles of $15 \mathrm{~s}$ at $95^{\circ} \mathrm{C}$ and $60 \mathrm{~s}$ at $60^{\circ} \mathrm{C}$. Each parameter $(\mathrm{LBF} n=10, \mathrm{HBF} n=10$ at 4 and $24 \mathrm{~h}$ ) was analysed in duplicate using MxProP Quantitative PCR machine and MxProP 3000 software (Stratagene, Amsterdam, Netherlands) and controls consisted of reactions in which reverse transcriptase template were absent. Gene expression was calculated using the $\Delta \mathrm{Ct}$ method where the genes of interest were normalised to the housekeeping gene Act1.

\section{Clustering and heat map analysis}

Differential expression of the selected genes from all isolates with $\operatorname{LBF}(\mathrm{n}=10)$ and $\operatorname{HBF}(\mathrm{n}=10)$ were assessed by clustering and heat map analysis using GenEx software (Exiqon, Vedbaek, Denmark). In brief, percentage expression data was pre-processed for log transformation and mean values calculated $(n=10$ for both LBF

and HBF) for each gene before heat map production. Each coloured cell in the heat map represents the variable expression of genes in LBF and HBF at 4 and $24 \mathrm{~h}$ time points. An increase in gene expression is represented by red and a down-regulation by green. Clustering techniques were used to show genes with similar expression patterns (co-regulated genes) in each set of isolates. The clustering was performed independently by average linkage and Euclidean distances used as a distance measure for both dimensions in the data.

\section{Statistical analysis}

Graph production, data distribution and statistical analysis were performed using GraphPad Prism (version 4; La Jolla, CA, USA). After assessing whether data conformed to a normal distribution data were transformed where necessary and One Way Analysis of Variance (ANOVA) was used to investigate significant differences between independent groups. A Bonferroni post-test was used to determine statistically significant differences between groups. The G. mellonella survival curve was analysed using log rank test. Student t-tests were used to measure statistical differences between the two independent groups assessed in gene expression studies. Statistical significance was achieved if $p<0.05$ IBM SPSS $^{\oplus}$ (version 20) statistical analysis software was used for correlation analysis. Two-tailed Spearman rho correlation coefficient was determined separately for all 4 and $24 \mathrm{~h}$ selected genes expression versus $24 \mathrm{~h}$ biomass data. Genes that had a significant correlation with biomass were tested for correlations with the other genes as described above.

\section{Additional files}

\begin{abstract}
Additional file 1: Figure S1. Optimisation of C. albicans biofilms. Standardised C. albicans SC5314 and 3153A ( $1 \times 10^{6}$ cells $\left./ \mathrm{mL}\right)$ were grown in flat-bottomed 96 well microtitre plates at $37^{\circ} \mathrm{C}$ for 24,48 and $72 \mathrm{~h}$ in RPMI-1640, YPD + 10\% FCS, YNB + 100mM glucose and Spider media. Negative controls were also included. Mature biofilms were carefully washed with PBS, air-dried and biomass quantified by staining each biofilm with $0.05 \% \mathrm{w} / \mathrm{v}$ crystal violet solution. The biofilms were washed and $100 \%$ ethanol applied to destain each biofilm. The biomass was quantified spectrophotometrically by reading absorbance at $570 \mathrm{~nm}$ in a microtitre plate reader (FluoStar Omega, BMG Labtech). Three replicates for each isolate were used and carried out on two separate occasions. Data represents mean \pm SEM. Significant differences were observed when comparing RPMI-1640 to all other growth media at $24 \mathrm{~h}\left({ }^{\S \S} \mathrm{p}<0.005\right.$, $\left.{ }^{\S \S} p<0.0001\right), 48 \mathrm{~h}\left({ }^{\#} p<0.005,{ }^{\# \#} p<0.0001\right)$ and $72 \mathrm{~h}\left({ }^{\dagger} p<0.05,{ }^{++t} p<0.0001\right)$. Significant differences were also found between periods of biofilm development within each growth media $\left({ }^{*} p<0.05,{ }^{* *} p<0.01\right)$.
\end{abstract}

Additional file 2: Table S1. Percentage gene expression in C. albicans 4 and $24 \mathrm{~h}$ biofilms.

\section{Abbreviations}

BSI: Bloodstream infections; ICU: Intensive care unit; CVC: Central venous catheter; ECM: Extracellular matrix; AMB: Amphotericin b; LBF: Low biofilm former; HBF: High biofilm former; CSH: Cell surface hydrophobicity; VRZ: Voriconazole; RPMI: Roswell park memorial institute; YPD: Yeast peptone dextrose; FCS: Fetal calf serum; YNB: Yeast nitrogen base; PBS: Phosphate 
buffered saline; CV: Crystal violet; XTT: 2,3-bis(2-methoxy-4-nitro-5-sulfophenyl)-2H-tetrazolium-5-caboxanilide; SEM: Scanning electron microscopy; MIC: Minimum inhibitory concentration; qPCR: Quantitative polymerase chain reaction; OM: Original magnification; FB: Fat body; SC: Subcuticle; PI: Paraintestinal; PT: Paratracheal; SD: Standard deviation.

\section{Competing interests}

None of the authors have any conflict of interest in publishing this work.

\section{Authors' contributions}

LS and RR participated in the study design, carried out the experimental studies on biofilms, performed statistical analysis and were responsible for the manuscript. DFL participated in study design, assisted with statistical support and helped draft the manuscript. FP, MF, DT and EB participated in study design and undertook the experimental work related to the $G$. mellonella model. BLJ and CW contributed to study design, data analysis and supervised manuscript writing. KS participated in QPCR analysis and manuscript writing. CJN participated in study design, analysis and supervised manuscript writing. GR conceived the study, participated in study design, data analysis and was responsible for writing and submission of the final manuscript. All authors read and approved the manuscript.

\section{Authors' information}

Infection and Immunity Research Group, Glasgow Dental School, School of Medicine, College of Medical, Veterinary and Life Sciences, University of Glasgow.

\section{Acknowledgements}

Margaret Mullin (University of Glasgow) for her assistance in scanning electron microscopy techniques.

\section{Author details}

'Infection and Immunity Research Group, Glasgow Dental School, School of Medicine, College of Medical, Veterinary and Life Sciences, University of Glasgow, 378 Sauchiehall Street, Glasgow G2 3JZ, UK. ${ }^{2}$ Laboratory of Microbiology, Department of Health Sciences, Università degli Studi di Milano, Milan, Italy. ${ }^{3}$ Division of Human Pathology, Department of Health Sciences, Università degli Studi di Milano, Milan, Italy. ${ }^{4}$ Institute of Healthcare Associated Infection, School of Health, Nursing and Midwifery, University of the West of Scotland, Paisley, UK. ${ }^{5}$ Microbiology Department, Glasgow Royal Infirmary, Glasgow, UK.

Received: 25 March 2014 Accepted: 24 June 2014

Published: 5 July 2014

\section{References}

1. Mensa J, Pitart C, Marco F: Treatment of critically ill patients with candidemia. Int J Antimicrob Agents 2008, 32(Suppl 2):S93-97.

2. Wisplinghoff $H$, Bischoff $T$, Tallent SM, Seifert $H$, Wenzel RP, Edmond MB: Nosocomial bloodstream infections in US hospitals: analysis of 24,179 cases from a prospective nationwide surveillance study. Clin Infect Dis 2004, 39(3):309-317.

3. Kojic EM, Darouiche RO: Candida infections of medical devices. Clin Microbiol Rev 2004, 17(2):255-267.

4. Lynch AS, Robertson GT: Bacterial and fungal biofilm infections. Annu Rev Med 2008, 59:415-428.

5. Ramage G, Rajendran R, Sherry L, Williams C: Fungal biofilm resistance. Int J Microbiol 2012, 2012:528521.

6. Taff HT, Nett JE, Zarnowski R, Ross KM, Sanchez H, Cain MT, Hamaker J, Mitchell AP, Andes DR: A Candida biofilm-induced pathway for matrix glucan delivery: implications for drug resistance. PLOS Pathog 2012, 8(8):e1002848

7. Uppuluri P, Chaturvedi AK, Srinivasan A, Banerjee M, Ramasubramaniam AK, Kohler JR, Kadosh D, Lopez-Ribot JL: Dispersion as an important step in the Candida albicans biofilm developmental cycle. PLOS Pathog 2010, 6(3):e1000828.

8. Tumbarello M, Posteraro B, Trecarichi EM, Fiori B, Rossi M, Porta R, de Gaetano DK, La Sorda M, Spanu T, Fadda G, Cauda R, Sanguinetti M: Biofilm production by Candida species and inadequate antifungal therapy as predictors of mortality for patients with candidemia. J Clin Microbiol 2007, 45(6):1843-1850
9. Daniels KJ, Park YN, Srikantha T, Pujol C, Soll DR: Impact of environmental conditions on the form and function of Candida albicans biofilms. Eukaryot Cell 2013, 12(10):1389-1402.

10. Kucharikova S, Tournu H, Lagrou K, Van Dijck P, Bujdakova H: Detailed comparison of Candida albicans and Candida glabrata biofilms under different conditions and their susceptibility to caspofungin and anidulafungin. J Med Microbiol 2011, 60(Pt 9):1261-1269.

11. Pierce CG, Uppuluri P, Tristan AR, Wormley FL Jr, Mowat E, Ramage G, Lopez-Ribot JL: A simple and reproducible 96-well plate-based method for the formation of fungal biofilms and its application to antifungal susceptibility testing. Nat Protoc 2008, 3(9):1494-1500.

12. Samaranayake $\mathrm{YH}$, Cheung BP, Parahitiyawa N, Seneviratne CJ, Yau JY, Yeung KW, Samaranayake LP: Synergistic activity of lysozyme and antifungal agents against Candida albicans biofilms on denture acrylic surfaces. Arch Oral Biol 2009, 54(2):115-126.

13. Galan-Ladero MA, Blanco-Blanco MT, Hurtado C, Perez-Giraldo C, Blanco MT, Gomez-Garcia AC: Determination of biofilm production by Candida tropicalis isolated from hospitalized patients and its relation to cellular surface hydrophobicity, plastic adherence and filamentation ability. Yeast 2013, 30:331-339.

14. Gamaletsou MN, Walsh TJ, Zaoutis T, Pagoni M, Kotsopoulou M, Voulgarelis M, Panayiotidis P, Vassilakopoulos T, Angelopoulou MK, Marangos M, Spyridonidis A, Kofteridis D, Pouli A, Sotiropoulos D, Matsouka P, Argyropoulou A, Perloretzou S, Leckerman K, Manaka A, Oikonomopoulos P, Daikos G, Petrikkos G, Sipsas NV: A prospective, cohort, multicentre study of candidaemia in hospitalized adult patients with haematological malignancies. Clin Microbiol Infect 2013, 20:050-057.

15. Blankenship JR, Mitchell AP: How to build a biofilm: a fungal perspective. Curr Opin Microbiol 2006, 9(6):588-594.

16. Tumbarello M, Fiori B, Trecarichi EM, Posteraro P, Losito AR, De Luca A Sanguinetti M, Fadda G, Cauda R, Posteraro B: Risk factors and outcomes of candidemia caused by biofilm-forming isolates in a tertiary care hospital. PLoS One 2012, 7(3):e33705.

17. Jose A, Coco BJ, Milligan S, Young B, Lappin DF, Bagg J, Murray C, Ramage G: Reducing the incidence of denture stomatitis: are denture cleansers sufficient? J Prosthodont 2010, 19(4):252-257.

18. Nett JE, Cain MT, Crawford K, Andes DR: Optimizing a Candida biofilm microtiter plate model for measurement of antifungal susceptibility by tetrazolium salt assay. J Clin Microbiol 2011, 49(4):1426-1433.

19. Blanco MT, Sacristan B, Lucio L, Blanco J, Perez-Giraldo C, Gomez-Garcia AC: Cell surface hydrophobicity as an indicator of other virulence factors in Candida albicans. Revista iberoamericana de micologia 2010, 27(4):195-199.

20. Bujdáková H, Didiášová M, Drahovská H, Černáková L: Role of cell surface hydrophobicity in Candida albicans biofilm. Cent Eur J Biol 2013, 8(3):259-262.

21. Perez A, Ramage G, Blanes R, Murgui A, Casanova M, Martinez JP: Some biological features of Candida albicans mutants for genes coding fungal proteins containing the CFEM domain. FEMS Yeast Res 2011, 11(3):273-284

22. Akins RA: An update on antifungal targets and mechanisms of resistance in Candida albicans. Med Mycol 2005, 43(4):285-318.

23. Cannon RD, Lamping E, Holmes AR, Niimi K, Tanabe K, Niimi M, Monk BC: Candida albicans drug resistance another way to cope with stress. Microbiology 2007, 153(Pt 10):3211-3217.

24. White TC: Increased mRNA levels of ERG16, CDR, and MDR1 correlate with increases in azole resistance in Candida albicans isolates from a patient infected with human immunodeficiency virus. Antimicrob Agents Chemother 1997, 41(7):1482-1487.

25. Nett JE, Crawford K, Marchillo K, Andes DR: Role of Fks1p and matrix glucan in Candida albicans biofilm resistance to an echinocandin, pyrimidine, and polyene. Antimicrob Agents Chemother 2010, 54(8):3505-3508.

26. Bachmann SP, VandeWalle K, Ramage G, Patterson TF, Wickes BL, Graybill JR, Lopez-Ribot JL: In vitro activity of caspofungin against Candida albicans biofilms. Antimicrob Agents Chemother 2002, 46(11):3591-3596.

27. Andes DR, Safdar N, Baddley JW, Playford G, Reboli AC, Rex JH, Sobel JD, Pappas PG, Kullberg BJ: Impact of treatment strategy on outcomes in patients with candidemia and other forms of invasive candidiasis: a patient-level quantitative review of randomized trials. Clin Infect Dis 2012, 54(8):1110-1122.

28. Cornely OA, Bassetti M, Calandra T, Garbino J, Kullberg BJ, Lortholary O, Meersseman W, Akova M, Arendrup MC, Arikan-Akdagli S, Bille J, Castagnola 
E, Cuenca-Estrella M, Donnelly JP, Groll AH, Herbrecht R, Hope WW, Jensen HE, Lass-Florl C, Petrikkos G, Richardson MD, Roilides E, Verweij PE, Viscoli C, Ullmann AJ: ESCMID* guideline for the diagnosis and management of Candida diseases 2012: non-neutropenic adult patients. Clin Microbiol Infect 2012, 18(Suppl 7):19-37.

29. Almirante B, Rodriguez D, Park BJ, Cuenca-Estrella M, Planes AM, Almela M, Mensa J, Sanchez F, Ayats J, Gimenez M, Saballs P, Fridkin SK, Morgan J, Rodriguez-Tudela JL, Warnock DW, Pahissa A: Epidemiology and predictors of mortality in cases of Candida bloodstream infection: results from population-based surveillance, barcelona, Spain, from 2002 to 2003. J Clin Microbiol 2005, 43(4):1829-1835.

30. Garey KW, Rege M, Pai MP, Mingo DE, Suda KJ, Turpin RS, Bearden DT: Time to initiation of fluconazole therapy impacts mortality in patients with candidemia: a multi-institutional study. Clin Infect Dis 2006, 43(1):25-31.

31. Kollef M, Micek S, Hampton N, Doherty JA, Kumar A: Septic shock attributed to Candida infection: importance of empiric therapy and source control. Clin Infect Dis 2012, 54(12):1739-1746.

32. Cirasola D, Sciota R, Vizzini L, Ricucci V, Morace G, Borghi E: Experimental biofilm-related Candida infections. Future Microbio/ 2013, 8(6):799-805.

33. Hasan $F$, Xess I, Wang $X$, Jain N, Fries BC: Biofilm formation in clinical Candida isolates and its association with virulence. Microbes Infect 2009, 11(8-9):753-761

34. Fuchs BB, Eby J, Nobile CJ, El Khoury JB, Mitchell AP, Mylonakis E: Role of filamentation in Galleria mellonella killing by Candida albicans. Microbes Infect 2010, 12(6):488-496.

35. Ramage G, VandeWalle K, Lopez-Ribot JL, Wickes BL: The filamentation pathway controlled by the Efg1 regulator protein is required for normal biofilm formation and development in Candida albicans. FEMS Microbiol Lett 2002, 214(1):95-100.

36. Lepak A, Nett J, Lincoln L, Marchillo K, Andes D: Time course of microbiologic outcome and gene expression in Candida albicans during and following in vitro and in vivo exposure to fluconazole. Antimicrob Agents Chemother 2006, 50(4):1311-1319.

37. Nailis H, Coenye T, Van Nieuwerburgh F, Deforce D, Nelis HJ: Development and evaluation of different normalization strategies for gene expression studies in Candida albicans biofilms by real-time PCR. BMC Mol Biol 2006, 7:25

38. Nett JE, Lepak AJ, Marchillo K, Andes DR: Time course global gene expression analysis of an in vivo Candida biofilm. J Infect Dis 2009, 200(2):307-313.

39. Nailis $H$, Kucharikova S, Ricicova M, Van Dijck P, Deforce D, Nelis H, Coenye T: Real-time PCR expression profiling of genes encoding potential virulence factors in Candida albicans biofilms: identification of model-dependent and -independent gene expression. BMC Microbiol 2010, 10:114.

40. Uppuluri P, Dinakaran $H$, Thomas DP, Chaturvedi AK, Lopez-Ribot JL: Characteristics of Candida albicans biofilms grown in a synthetic urine medium. J Clin Microbiol 2009, 47(12):4078-4083.

41. Mukherjee PK, Chandra J, Kuhn DM, Ghannoum MA: Mechanism of fluconazole resistance in Candida albicans biofilms: phase-specific role of efflux pumps and membrane sterols. Infect Immun 2003, 71(8):4333-4340.

42. Ramage G, Bachmann S, Patterson TF, Wickes BL, Lopez-Ribot JL: Investigation of multidrug efflux pumps in relation to fluconazole resistance in Candida albicans biofilms. J Antimicrob Chemother 2002, 49(6):973-980.

43. Ramage G, Coco B, Sherry L, Bagg J, Lappin DF: In vitro Candida albicans biofilm induced proteinase activity and SAP8 expression correlates with in vivo denture stomatitis severity. Mycopathologia 2012, 174(1):11-19.

44. Joo MY, Shin JH, Jang HC, Song ES, Kee SJ, Shin MG, Suh SP, Ryang DW: Expression of SAP5 and SAP9 in Candida albicans biofilms: comparison of bloodstream isolates with isolates from other sources. Med Mycol 2013 , 51(8):892-896

45. Nailis $\mathrm{H}$, Vandenbroucke $\mathrm{R}$, Tilleman $\mathrm{K}$, Deforce $\mathrm{D}$, Nelis $\mathrm{H}$, Coenye T: Monitoring ALS1 and ALS3 gene expression during in vitro Candida albicans biofilm formation under continuous flow conditions. Mycopathologia 2009, 167(1):9-17.

46. Zhao X, Daniels KJ, Oh SH, Green CB, Yeater KM, Soll DR, Hoyer LL: Candida albicans Als $3 p$ is required for wild-type biofilm formation on silicone elastomer surfaces. Microbiology 2006, 152(Pt 8):2287-2299.

47. Liu Y, Filler SG: Candida albicans Als3, a multifunctional adhesin and invasin. Eukaryot Cell 2011, 10(2):168-173.
48. Li F, Svarovsky MJ, Karlsson AJ, Wagner JP, Marchillo K, Oshel P, Andes D, Palecek SP: Eap1p, an adhesin that mediates Candida albicans biofilm formation in vitro and in vivo. Eukaryot Cell 2007, 6(6):931-939.

49. Nobile CJ, Nett JE, Hernday AD, Homann OR, Deneault JS, Nantel A, Andes DR, Johnson AD, Mitchell AP: Biofilm matrix regulation by Candida albicans Zap1. PLoS Biol 2009, 7(6):e1000133.

50. Ramage G, Vande Walle K, Wickes BL, Lopez-Ribot JL: Standardized method for in vitro antifungal susceptibility testing of Candida albicans biofilms. Antimicrob Agents Chemother 2001, 45(9):2475-2479.

51. Erlandsen SL, Kristich CJ, Dunny GM, Wells CL: High-resolution visualization of the microbial glycocalyx with low-voltage scanning electron microscopy: dependence on cationic dyes. J Histochem Cytochem 2004, 52(11):1427-1435.

52. Yoshijima Y, Murakami K, Kayama S, Liu D, Hirota K, Ichikawa T, Miyake $Y$ : Effect of substrate surface hydrophobicity on the adherence of yeast and hyphal Candida. Mycoses 2010, 53(3):221-226.

53. Rosenberg M, Gutnick D, Rosenberg E: Adherence of bacteria to hydrocarbons: a simple method for measuring cell-surface hydrophobicity. Med Microbiol 1980, 9:29-33.

54. Cotter G, Doyle S, Kavanagh K: Development of an insect model for the in vivo pathogenicity testing of yeasts. FEMS immunology and medical microbiology 2000, 27(2):163-169.

55. Gago S, Garcia-Rodas R, Cuesta I, Mellado E, Alastruey-Izquierdo A: Candida parapsilosis, Candida orthopsilosis, and Candida metapsilosis virulence in the non-conventional host Galleria mellonella. Virulence 2014, 5(2):278-285.

56. Fallon J, Kelly J, Kavanagh K: Galleria mellonella as a model for fungal pathogenicity testing. Methods Mol Biol 2012, 845:469-485.

57. Finkel JS, Mitchell AP: Genetic control of Candida albicans biofilm development. Nat Rev Microbiol 2011, 9(2):109-118.

doi:10.1186/1471-2180-14-182

Cite this article as: Sherry et al:: Biofilms formed by Candida albicans bloodstream isolates display phenotypic and transcriptional heterogeneity that are associated with resistance and pathogenicity. BMC Microbiology 2014 14:182.

\section{Submit your next manuscript to BioMed Central and take full advantage of:}

- Convenient online submission

- Thorough peer review

- No space constraints or color figure charges

- Immediate publication on acceptance

- Inclusion in PubMed, CAS, Scopus and Google Scholar

- Research which is freely available for redistribution 